\title{
Laboreal
}

Volume 13 №2 | 2017

Varia

\section{Violencia y trabajo}

violência e trabalho

Violence et travail

Violence and work

\section{Laerte Idal Sznelwar}

Traductor. Patricio Nusshold

\section{OpenEdition}

\section{Journals}

Edición electrónica

URL: http://journals.openedition.org/laboreal/400

DOI: $10.4000 /$ laboreal. 400

ISSN: 1646-5237

Editor

Universidade do Porto

Referencia electrónica

Laerte Idal Sznelwar, «Violencia y trabajo », Laboreal [En línea], Volume 13 №2 | 2017, Publicado el 01 diciembre 2017, consultado el 15 septiembre 2020. URL : http://journals.openedition.org/laboreal/400

Este documento fue generado automáticamente el 15 septiembre 2020

\section{(c) (†) \&)}

Laboreal está licenciado com uma Licença Creative Commons - Atribuição-NãoComercial 4.0 Internacional. 


\title{
Violencia y trabajo
}

\author{
violência e trabalho \\ Violence et travail \\ Violence and work \\ Laerte Idal Sznelwar
}

Tradución : Patricio Nusshold

\section{NOTA DEL EDITOR}

http://dx.doi.org/10.15667/laborealxiii0217lses

1 Tratar la cuestión de la violencia en el trabajo es un gran desafío, en tanto existen toda una serie de discusiones y polémicas acerca de cómo definir qué es la violencia y cómo distinguirla de otro tipo de fenómenos relacionados con las relaciones humanas. En el caso específico de muchas personas que trabajan, diferentes modos de relación moldeados por la organización del trabajo son, de alguna manera, fuente de sufrimiento patógeno. Sin embargo, no es posible categorizar todos los tipos de insatisfacción como violencia, en tanto existe un riesgo elevado de banalización y pérdida del poder de caracterización y de comprensión de sus orígenes y de como se disemina en los ambientes de trabajo. Caracterizar aquello que entendemos por violencia en un determinado contexto es importante para poder responsabilizar efectivamente a quienes, de alguna manera, actúan violentamente.

2 Las definiciones más frecuentes distinguen daños físicos, psíquicos y sociales para caracterizar un acto violento. Sin embargo, a pesar de poder distinguirlos no hay modo de separarlos, en tanto la experiencia vivida por quien sufre del uso de la coerción ejercida por otro es vivenciada en todas esas dimensiones. Esto se debe a que no hay modo de separar el daño físico del daño moral, en tanto no podemos considerar que existe una separación entre cuerpo y psiquis. Ambos se encuentran siempre involucrados cuando se trata del resultado de un acto violento. Sin embargo, la acción 
de quien (es) tiene (n) la intención de alcanzar a otro y causarle daños, puede estar orientada, en un primer momento, hacia el cuerpo o la mente.

3 La violencia es siempre relacional, fruto de la acción de alguien o incluso de varias personas dirigida a otro. En el caso de las situaciones laborales podemos considerar que existe todo un espectro de acciones que pueden ser consideradas como violentas, desde las más explícitas hasta las más sutiles, poco perceptibles para quienes no están directamente involucrados.

4 Dentro de las más diversas profesiones, existen aquellas en las que la violencia siempre se encuentra presente, porque se trata de actividades humanas que tienen que ver con, por ejemplo, la seguridad pública. En esos casos, los profesionales actúan para prevenir o contener actos violentos de otros, estando autorizados por el Estado para utilizar la fuerza para que los objetivos de seguridad puedan alcanzarse. Incluso habiendo recibido algún tipo de preparación para que esos profesionales tengan las habilidades para actuar frente a situaciones en las cuales el otro es la fuente de peligro, muchas acciones de esos profesionales derivan en dirección de la violencia, siendo ellos también agentes del pasaje al acto. Todo eso a pesar del hecho que su papel sea principalmente dirigido a apaciguar las relaciones sociales. ¿Cuáles son las consecuencias para estos trabajadores y para aquellos que sufren actos violentos, tanto en términos físicos como morales? Ya que de hecho, nadie está siendo protegido.

5 Sin embargo, existen otros trabajos en los que los trabajadores están sometidos a un tipo de violencia, y en los cuales se muestra la importancia del sufrimiento patógeno en ciertas categorías profesionales, incluyendo casos de suicidio.

6 En otras situaciones, los profesionales que actúan en situaciones de servicio se confrontan con actos violentos de otros sujetos, actos realizados por ciudadanos, usuarios, clientes con los cuales se relacionan en sus actividades cotidianas. En esos casos, a pesar de no haber algo relacionado directamente con la violencia en sí, existen situaciones de conflicto de intereses que pueden desencadenarla. Lamentablemente no son raras las situaciones en las que los agentes, en servicios públicos y privados, viven situaciones de franca agresión, sea a través de la palabra o de agresiones físicas. La experiencia de ser agredido redunda, muchas veces, en grandes dificultades en relación al trabajo. La pérdida del sentido de aquello que hacen, o el miedo a encontrarse nuevamente en una situación similar pueden contribuir al desarrollo del sufrimiento patógeno que se expresa en diferentes trastornos de la salud, como pueden ser los síndromes de estrés post-traumáticos o la depresión, entre otros.

7 Esta cuestión relacional vinculada al contacto con el público, generalmente es considerada por las modalidades de organización del trabajo y por los dispositivos de evaluación del desempeño. Los problemas que resultan pueden estar fuertemente ligados a los procesos de individualización donde los compañeros pueden competir por algún beneficio, financiero o de otro orden, como una promoción o la posibilidad de obtener ciertos recursos. Sin embargo, existen muchas situaciones en las cuales el trabajador poco puede hacer por la otra persona. En esos casos, el riesgo de ser agredido aumenta, especialmente si se encuentra aislado. Conviene resaltar que incluso existen casos en los que, aun sabiendo que tiene razón, no tiene autonomía para lograr implementar una solución más adecuada. Este escenario, que puede ser desolador, se encuentra al origen de muchos conflictos y de la explosión de episodios de violencia, por parte de quién se encuentra en contacto con el trabajador. 
8 En ambientes en los cuales existe un alto grado de competencia entre colegas, y en los que aquello que más importa es alcanzar metas anteriormente definidas por la jerarquía, existe un fuerte riesgo de encontrarse aislado y fragilizado ante situaciones de acoso. Por un lado, se encontrarían sujetos a presiones de la jerarquía, presiones que extrapolan aquello que sería legítimo en relación a trabajar bien y eficientemente y, por otro lado, no poder contar con la solidaridad de los compañeros, en tanto todos se encuentran compitiendo entre sí. Se trata de una violencia sutil, menos evidente, pero que también puede ser considerada como tal, sobre todo por tratarse de un tipo de acción que tiene como fin causar daño a esa persona. La inexistencia de espacios de intercambio acerca de la experiencia y de deliberación colectiva genera un terreno propicio para la construcción de escenarios de producción en los cuales la violencia emerge. Se trata de escenarios en los que se le considera al otro como objeto, en procesos de reificación, donde se refuerzan diferentes modos de clivaje en las relaciones sociales y en relación a la economía psíquica de cada uno.

9 La relación entre violencia y desempleo también es importante. A pesar de que no es posible establecer una relación directa, del estilo causa y efecto, la pérdida del sentido de utilidad social y el consecuente refuerzo de la identidad coloca al sujeto en una situación de fragilidad, en la cual la violencia, tanto hacia los otros como hacia sí mismo, puede emerger. Esto tiende a suceder con mayor frecuencia cuando el papel del trabajo, con su potencial sublimatorio, se pierde. El desempleo, fenómeno muy frecuente en nuestros sistemas económicos es, potencialmente, un factor generador o que potencia de la violencia.

10 La violencia contra sí mismo también precisa ser considerada. Los procesos de autoagresión se tornaron más conocidos en el espacio público debido a los casos de suicidio infelizmente con una incidencia creciente en el mundo del trabajo. Se trata de un debate aún más complicado, en tanto al tratar la violencia de otro, podemos caracterizarlo como un acto dirigido e intencional, fruto de algún tipo de estrategia de poder, de dominación. En el caso de los procesos contra sí mismo, es necesario considerar la importancia de los mecanismos inconscientes que, en el ámbito de la economía psíquica, se encuentran relacionados con el propio sujeto. Cabe incluso considerar que, aún en el caso de los actos de violencia ejercidos contra otro, no se trata solo de acciones conscientes y pensadas como estrategia de dominación ligados a modos de relación social moldeados por decisiones organizacionales que refuerzan los mecanismos inconscientes del clivaje. El pasaje al acto y la violencia tienen que ver con la irrupción de aquello que quedó, de alguna manera, relegado, escondido.

11 Cabe resaltar que este pequeño texto debe ser considerado apenas como una introducción al tema, bastante incompleta. Existe una vasta literatura, así como grupos de estudio y promotores de políticas públicas que tratan esta cuestión. Un importante trabajo de reflexión sobre la temática fue publicado en un libro coordinado por Christophe Dejours (2007), desarrollado en cooperación con otros autores. 
BIBLIOGRAFÍA

Dejours, C. (sous la direction de) (2007). Conjurer la violence : travail, violence et santé. Paris : Payot et Rivages.

ÍNDICE

Temas: o Dicionário

\section{AUTORES}

\section{LAERTE IDAL SZNELWAR}

Departamento de Engenharia de Produção Escola Politécnica

Universidade de São Paulo

Av. Professor Almeida Prado, trav. 2 no 128 - CEP 05508-900, Cidade Universitária, São Paulo - SP Brasil

laertesz@usp.br 